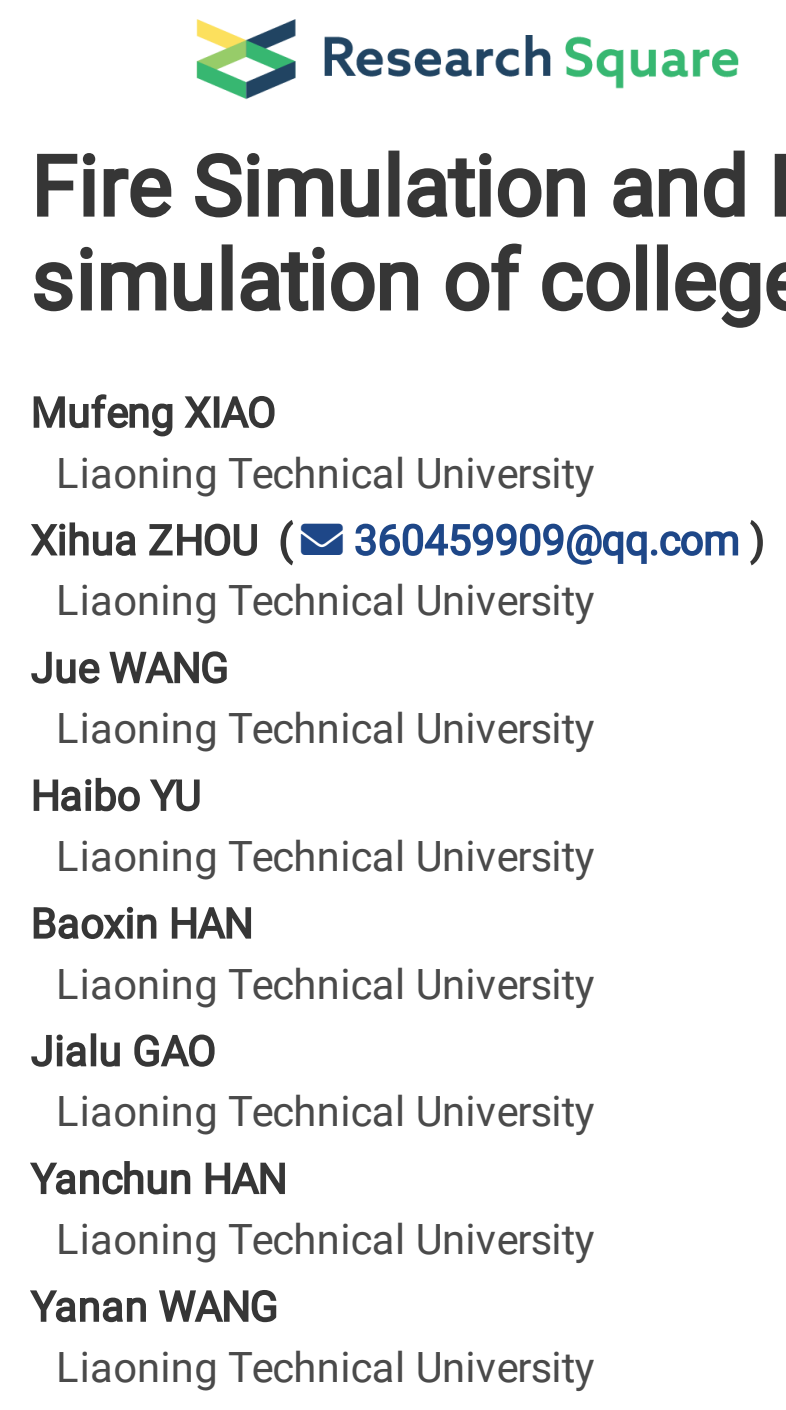

\author{
Mufeng XIAO \\ Liaoning Technical University \\ Xihua ZHOU ( $\nabla 60459909 @ q q . c o m$ ) \\ Liaoning Technical University \\ Jue WANG \\ Liaoning Technical University \\ Haibo YU \\ Liaoning Technical University

\section{Baoxin HAN} \\ Liaoning Technical University \\ Jialu GAO \\ Liaoning Technical University \\ Yanchun HAN \\ Liaoning Technical University \\ Yanan WANG \\ Liaoning Technical University
}

\title{
Fire Simulation and Emergency evacuation simulation of college student apartment
}

\section{Research Article}

Keywords: College apartment, Fire simulation, Emergency evacuation

Posted Date: February 1st, 2022

DOI: https://doi.org/10.21203/rs.3.rs-1270622/v1

License: (c) (i) This work is licensed under a Creative Commons Attribution 4.0 International License.

Read Full License 


\section{Abstract}

The relative concentration of personnel in student apartments in colleges and frequent safety incidents have seriously affected the lives and property safety of students. Therefore, it is of great significance to study the fire in college apartments and its emergency evacuation.Based on the size and volume of No. 4 student dormitory building in the North Campus of Liaoning Technical University,this study use Pyrosim software to carry out fire numerical simulation. The variation rules of smoke visibility, $\mathrm{CO}$ concentration, and ambient temperature in the college student apartment building were analyzed and the available safe evacuation time was determined. Moreover, the Pathfinder software was used to carry out emergency evacuation simulation with the combination of physical signs, evacuation speed and personnel proportions, etc.It can analyze the influence of factors such as the number of evacuated persons on each floor of the college student apartment and the layout of the building's staircase on the evacuation time.The result shows:visibility change characteristics have a greater impact on evacuation and rescue,the original layout of the student apartment cannot satisfy the safe evacuation of all personnel,the bottleneck areas for emergency evacuation are indoor corridors and evacuation stairs;increasing the number of evacuation exits in the stairwell can effectively improve the efficiency of escape;when the number of students on each level reaches a certain value, restrictions must be taken, etc. The research results can provide a basis for the reasonable planning and management of evacuation passages in college student apartments.

\section{Introduction}

University apartments are relatively concentrated places for college students. At the same time, unexpected accidents are common, which cause a great threat to the personnel and have impact on the property safety of the most students. According to CCTV statistics[1], more than 2,000 fires occurred in the dormitories of Chinese colleges and universities in the past five years. On average each dormitory catches fire every day. In a fire accident, students' awareness of fire safety is considerably weak and they lake of survival skills, which leads to a large number of casualties and property losses. Therefore, the law about the spread of fire smoke in university apartments and the emergency evacuation of personnel have gradually become two hot spots for scholars who already have done some research at home and abroad. Literature [2] comparatively studies the evacuation behavior and psychology of personnel both under panic and normal conditions and verifies the impact of personnel psychological status on evacuation. Literature [3] uses CFD technology to simulate the law of smoke movement in interconnected corridors, studies the transient field model and provides guidance for the design of corridor smoke prevention and personnel evacuation. Literature $[4,5]$ put forward the evacuation model of personnel response which specifically analyzes the behavior and changes of people in the fire and guides the evacuation of people in the fire, etc. Literature [6] does research on the psychological state and behaviors of people and analyzes the impact of circumstance on people and psychological behavior of the human body in the fire. Literature [7] uses Pathfinder and FDS to study the evacuation of people in high-rise buildings when fire occurs and obtains the time which is enough for people to escape in different situations. Literature $[8,9]$ 
use questionnaires and emergency evacuation drills to investigate and analyze the psychology and behavior of college students during building fires. The results show that women and people with low levels of awareness take longer to evacuate. Literature $[10,11]$ summarize the possible psychology of people as panic and aggregation while they are in a multi-storey building fire, analyze reasons and provide targeted suggestions for the evacuation. The literature $[12,13]$ analyze the dynamic characteristics while the crowd were evacuating during a fire and establish the state equation of the stream of people. Literature [14] uses Anylogic simulation software to analyze the impact of evacuation efficiency with building obstacles in different size and position while the male and female students are on the emergency evacuation in college apartments. Literature [15] uses Pathfinder software to design an evacuation plan and analyzes indicators such as the number of evacuated person, the number of exits, the width of exits and stairs. Literature [16] uses the questionnaire survey method to analyze the characteristic parameters of crowd evacuation behavior and simulates the evacuation situation when a fire occurs in a male or female dormitory. Literature [17] uses Pathfinder software to model a university library building and simulates simulation that based on personnel load, personnel physical signs, evacuation speed and personnel ratio, etc and analyzes influence of factors such as the stacking quantity, location and number of evacuated items on the evacuation time.There are also many scholars who have carried out research on the emergency evacuation simulation of university buildings[18-21].

This paper takes Building No. 4 of the student apartment building on the North Campus of Liaoning Technology University as an example, and uses Pyrosim and Pathfinder software to carry out numerical simulation research. When a fire occurs in a student apartment in a university, the environmental temperature, visibility, $\mathrm{CO}$ concentration, and personnel composition, number, and stairwell planning are analyzed. etc., the impact on safe evacuation, etc. It provides a basis for the fire safety management of college students' apartment buildings, the evacuation of fire emergency personnel and the preparation of emergency plans.

\section{Numerical Modeling And Fire Simulation \\ 2.1 Introduction to PyroSim and simulated objects}

Pyrosim is the leading software for fast and accurate use of FDS models, helping users to quickly create and manage the details of complex fire models. At the same time, Pyrosim also provides a property library that can be customized and imported into the current model, such as: reactions, heat detectors, materials, particles, surfaces and other model parameters. Because of its powerful functions, it is widely used in the research of building fire, tunnel fire, high-rise building fire and so on.

Therefore, this paper chooses PyroSim software to perform numerical simulation analysis on the fire scene of college student apartments.Fig. 1 is a comparison of the scene photos and BIM model of the 4\# building of the college student apartment building in the north campus of Liaoning Technology University .The building has 6 floors and the total height of the building is $23.05 \mathrm{~m}$. The main entrance on the ground floor is equipped with a duty room, storage room, etc.Floors 1-6 are all six-bed student dormitories.A total 
of 160 rooms, one of which is a barrier-free dormitory.The building can accommodate 960 students to sleep.And the building area is 5712.12 square meters. The standard floor plan is shown in Fig. 2.

\subsection{Model building}

In this study, the Revit software was used to establish the physical model of fire in a prefabricated building, and the Revit model was then imported into PyroSim. The model renderings and standard floor plans are shown in Figs. 3 and 4. Using the ratio of 1:1, the simulation model was constructed and the model area was divided into grids to simulate a fire scene. If the grid division is too large, it may not accurately calculate and describe the change of the environmental parameters in the fire scene. If the grid division is too small, the accuracy of the simulation calculation will be higher, which may result in excessively long or infeasible calculation. Therefore, by comprehensively considering the calculation accuracy, this study adopted the uniform mesh partition method, and the mesh size was set to $1 \mathrm{~m} \times 1 \mathrm{~m}$ $\times 1 \mathrm{~m}$.

\subsection{Fire hazard determination}

\subsubsection{Analysis on influencing factors of fire in college student apartment}

According to relevant statistics, most human casualties during a fire get hurt and coma before death are caused by the inhalation of smoke and toxic gas. When a fire breaks out, the factors that can threaten the safe evacuation of people are the smoke visibility, toxic smoke (mainly $\mathrm{CO}$ ), and heat radiation from the fire source [22]. The $\mathrm{CO}$ concentration, flue gas temperature, flue gas layer height, and flue gas visibility are the main performance parameters. Therefore, the critical values of human tolerance to these parameters should be analyzed to determine whether a fire situation has reached the dangerous state.

\section{(1) Smoke layer height}

The height of the smoke layer determines whether the smoke will affect the human body or not. The hightemperature smoke produces in a fire will rise to the upper space of the building under the action of thermal buoyancy. When the smoke encounters the roof of the building, it accumulates and gradually thickens to form a smoke layer. As the smoke continues to rise and the smoke layer continues to thicken, the height of the smoke layer gradually decreases; when the layer of smoke falls to reach the fire, harm is occurred on the personnel and the evacuation process is deeply affected. Therefore, the smoke layer should be kept above a certain height to ensure the safety of personnel and rapid evacuation to a greater extent. One of the quantitative assessment criteria is that the height of the smoke layer should satisfy the following formula in the process of personnel evacuation.

$H_{s} \geq H_{c}=H_{p}+0.1 H_{B}(1)$ 
where HS is the clear height $(\mathrm{m})$; $\mathrm{HC}$ is the critical height $(\mathrm{m})$; $\mathrm{Hp}$ is the average height $(\mathrm{m})$ and typically amounts to $1.6 \mathrm{~m}$; HB is the height inside the building $(\mathrm{m})$.

The average height of the college student apartment project was approximately $3.6 \mathrm{~m}$. According to Equation 1, the critical height $\mathrm{HC}=1.6+0.1 \times 3.6=1.96(\mathrm{~m})$. Therefore, the height of $2.00 \mathrm{~m}$ above the ground was considered as the critical height of the smoke layer.

(2) Flue gas temperature

When a fire breaks out, hot smoke is typically produced, and people breathing the overheated air may suffer heat stroke and skin burns. Because thermal radiation data cannot be obtained directly, it is necessary to determine the critical temperature that the human body can withstand by analyzing the fire hazard conditions. The tolerance times of the human body under different conditions are listed in Table 1. The critical value of the selected temperature is $60^{\circ} \mathrm{C}$.

Table 1

Limit of human body tolerance to hot air [23].

\begin{tabular}{|llll|}
\hline $\begin{array}{l}\text { Temperature and } \\
\text { Humidity }\end{array}$ & $\begin{array}{l}<60^{\circ} \mathrm{C} \text {, Water } \\
\text { saturation }\end{array}$ & $\begin{array}{l}60^{\circ} \mathrm{C} \text {, Moisture content } \\
<1 \%\end{array}$ & $\begin{array}{l}100^{\circ} \mathrm{C}, \text { Moisture } \\
\text { content }<1 \%\end{array}$ \\
\hline Tolerance time $(\mathrm{min})$ & $>30$ & 12 & 1 \\
\hline
\end{tabular}

(3) CO concentration

A large amount of high-temperature smoke is produced during a fire, and there are many types of combustibles in buildings, including various toxic and harmful gases and solid particles, among which the $\mathrm{CO}$ content is the largest and most harmful to the human body, results in complex fire smoke composition. After $\mathrm{CO}$ gas poisoning, carbonyl hemoglobin is produced in the blood and affects the human respiration and nerve reaction. The degrees of harm of different $\mathrm{CO}$ concentrations to the human body are listed in Table 2. According to the hazard assessment, the CO concentration of $500 \mathrm{ppm}$ is determined as the critical value for the emergence of danger.

Table 2

Degree of harm to human body of different CO concentrations [24].

\begin{tabular}{|lll|}
\hline CO concentration of flue gas (ppm) & Time $(\mathrm{min})$ & Degree of hazard \\
\hline 200 & $120-180$ & Mild headache and fatigue \\
\hline 400 & $60-120$ & Secondary headaches \\
\hline 800 & 45 & Unconsciousness, vomiting \\
\hline 1600 & 20 & Headache, dizziness, nausea \\
\hline 3200 & $10-15$ & Death \\
\hline
\end{tabular}


(4) Smoke visibility

The visibility of flue gas determines people's capability of assessing the surroundings and recognizing the evacuation passageway and safety exit, the perception and decision-making. The escape time, and other factors affect the efficiency of an emergency evacuation. Low visibility results from the blocking of light by the solid particles in flue gas. In a low-visibility environment, the suspended solid particles stimulate the eyes, make it difficult for trapped people to accurately assess the surrounding environment, and reduce people's ability to recognize the evacuation channels and safety exits, which results in perceptual decision-making mistakes and missing the optimal escape time. The Australian "Fire Engineer Guide" specifies the critical value of visibility for spaces with different size. The critical value of visibility is $10 \mathrm{~m}$ in a large space and $5 \mathrm{~m}$ in a small space [25].The college student apartment project has small space; therefore, the smoke visibility index is $5 \mathrm{~m}$.

\subsubsection{Fire hazard determination conditions}

Through the analysis of the above-mentioned factors influencing the safety of personnel evacuation, the temperature, $\mathrm{CO}$ concentration, and visibility conditions in the fire scene should be set to ensure the safe evacuation of construction personnel. This study set the fire risk assessment conditions of the college student apartment project as follows:

(1) Temperature assessment conditions: a smoke layer temperature exceeding $60^{\circ} \mathrm{C}$ at a height of $2.00 \mathrm{~m}$ above the ground is considered as a fire danger state.

(2) $\mathrm{CO}$ concentration assessment conditions: a $\mathrm{CO}$ concentration greater than $500 \mathrm{ppm}$ at a height of $2.00 \mathrm{~m}$ above the ground is considered as a fire danger state;

(3) Visibility assessment conditions: if the visibility of the smoke layer at $2.00 \mathrm{~m}$ above the ground is less than $5 \mathrm{~m}$, it is considered that the fire has reached the dangerous state.

\subsection{Fire scene setup}

Initial simulation environment: the flow field in the room is static, the temperature is $20^{\circ} \mathrm{C}$, and the pressure is standard atmospheric pressure. Due to the large number of people in college apartments, the electrical wiring is complicated. This article simulates a fire caused by an electrical fire in the dormitory. The fire point is located in the middle dormitory on the west side of the 2nd floor.To monitor the spread of fire, the visibility and temperature change characteristics of escape routes. A number of temperature sensors, $\mathrm{CO}$ concentration detectors, smoke layer height detectors and visibility detectors are all set on each floor. And the height is $2 \mathrm{~m}$ above the ground of the floor, as shown in Fig. 5.

\subsection{Analysis of fire simulation results}

\subsubsection{Fire smoke spread analysis}


Figure 7 shows the process of simulating the spread and filling of smoke in the student apartment after a fire. It can be seen from the simulation results of Fig. $6(\mathrm{a}) \otimes(\mathrm{f})$ that the smoke mainly gathered around the fire source at the initial stage of combustion of the fire source at $30 \mathrm{~s}$; When the fire broke out for $90 \mathrm{~s}$, the smoke on the 2 nd floor was spreading rapidly upwards through the stairwell. When the fire broke out for 150s, the smoke generated by the fire source on the second floor which spread to the top floor and the outside of the student apartment through the windows on the north side. At this time, the smoke did not fill the entire corridor passageway on the second floor yet. As the fire continued to develop, the smoke continued to spread and the smoke concentration gradually increased; At $t=270$ s, the middle and north areas of the 3rd and 4th floors were completely filled with smoke; When the time moved to $360 \mathrm{~s}$, the floors above 2 floor were mostly filled with smoke; 480 s after the fire broke out, the smoke continued to spread and the entire office building was filled about $75 \%$.

\subsubsection{Temperature change analysis}

The temperature change curve and the temperature change slice diagram are drawn in Figs. 7 and 8. According to the temperature change data which obtained by the temperature sensor, through the analyzing the conclusion of temperature change curve are obtained: (1) the fire location exhibits approximately the same change trend, which reveals that, after the initial stage of fire combustion, the temperatures soars to the maximum temperature fluctuation and then declines. With the spread of the fire, the temperature began to rise after reaching the lowest point, and the temperature tended to be stable with the development of time. (2) When fire occurs, the temperature at the fire source linearly increases. It can easily cause severe threats to the life and safety of personnel close to the fire source. Hence, it is very important for people to escape the danger immediately and stay away from the fire source. (3) The temperature change trends at the exit of each stairs are the same and the temperature change is relatively slow; as the distance to the fire decreases, the temperature change becomes faster.(4) According to the above discussion, the ambient temperature limit of the human body is approximately $60^{\circ} \mathrm{C}$. Within $500 \mathrm{~s}$, no sensor data exceeds $60^{\circ} \mathrm{C}$, indicating that temperature changes have no effect on personnel escape.

\subsubsection{CO concentration change analysis}

Under the action of plume, the buoyancy of the flue gas increases and the flue gas rapidly rises to the ceiling. The produced flue gas jets to the ceiling and rapidly spreads to both sides of the corridor along the ceiling. The carbon monoxide concentration is maximum at the detection point farthest from the fire source, where a large amount of flue gas has accumulated. Under the positive chimney effect, hot flue gas is gradually injected into each floor over time. The flue gas in the stairwell is affected by the positive chimney effect, and the temperature of the flue gas increases; therefore, the flue gas produces greater buoyancy. Under these conditions, a large number of high temperature flue gas moves to the upper layer. However, during the movement, the flue gas is hampered by the staircase structure, and a large amount of high temperature flue gas accumulates at the stairs, which leads to a further increase in the flue gas temperature. Hence, the flue gas produces stronger buoyancy, and the temperature flue gas action is high until the gas moves to the top of the stairs. Additionally, at 5 layer detection points, the carbon monoxide concentration is higher relative to other floors, and thus more dangerous, as shown in Figs. 9 and 10. 
When the height of the smoke layer is lower than the height of the human eye, the carbon monoxide concentration at all detection points does not reach the critical value during the simulation time, and the carbon monoxide is not harmful to humans.

\subsubsection{Visibility change analysis}

In the process of combustion, solid and liquid particles are mass produced in large number, which deeply affects the visibility of the fire site and produces huge resistance for the emergency evacuation of personnel and successfully putting out of the fire. Therefore, this study installed visibility sensors at the same positions as the temperature sensors. The visibility curve was drawn according to the sensor data. As shown in Figs. 11 and 12, in the early stage of the fire, the visibility of the floor was approximately 30 $\mathrm{m}$ and decreased exponentially as smoke filled the office building with the fire spreading. Owing to the impact of the fire source on the second floor, the visibility of the sensor decreased very early. The visibility dropped to $5 \mathrm{~m}$ in $200 \mathrm{~s}$ and reached the danger point for casualties. At approximately $400 \mathrm{~s}$, the data collected by all visibility sensors reveal that the visibility at each exit was less than $5 \mathrm{~m}$. The optimal escape time elapses after $400 \mathrm{~s}$.

\section{Establishment Of Numerical Model And Emergency Evacuation Simulation}

\subsection{Evacuation software contrast with Pathfinder software Introduction}

Pathfinder is an emergency evacuation system software developed by Thunderhead Engineering. It provides the simulation design and execution of a graphical user interface, as well as the analysis results of three-dimensional visualization tools; at the same time, the model can also calculate the independent movement of each person and give a set of Unique parameters (top speed, choice of exit, etc.). Pathfinder has been widely used in the evacuation simulation research of people in densely populated places such as subways, shopping malls, and floors. Therefore, this study uses Pathfinder software to simulate the evacuation process of the student groups in college apartment.

\subsection{Establishment of emergency evacuation environment}

this study converted the safety information model of the college student apartment project into the DXF format and imported it into Pathfinder software. The model was simplified, and the floor, stairs, doors, other components, and evacuation routes were identified. The BIM safety information model, Pathfinder evacuation model, and personnel distribution in an evacuation scenario are shown in Figs. 13 and 14 .

\subsection{Set emergency evacuation parameters}

(1) Set personnel load 
The student apartment has 6 floors. It has a total of 160 rooms, all of which are 6-person rooms, which can accommodate 960 people. During the daytime, due to the different class hours of students from different majors and different grades. The distribution of personnel between floors is also different and the total number of students is relatively small. The distribution of people after going to bed at night until the next morning is relatively even and the total number of people is the largest. This simulation adopts the most unfavorable principle to simulate the situation when the students are fully loaded and evenly distributed. The distribution of personnel on each floor is shown in Table 3.

Table 3

Maximum number of people on each floor

\begin{tabular}{|lllllll|}
\hline Floor & $\mathbf{1}$ & $\mathbf{2}$ & $\mathbf{3}$ & $\mathbf{4}$ & $\mathbf{5}$ & $\mathbf{6}$ \\
\hline Number of people & 150 & 162 & 162 & 162 & 162 & 162 \\
\hline
\end{tabular}

(2) Set gender ratio

Since the college apartment simulated in this paper is a female dormitory, $100 \%$ of them are female, and all of them are young people.

(3) Set up personnel signs

Personnel parameters set in Pathfinder include shoulder width, height and different working surface speed settings. The accurate setting of personnel parameters can make the evacuation simulation results closer to the escape situation under real fire conditions.Based on "Chinese Adult Human Dimensions" (GB/T10000-1988)[26], according to survey data, the average shoulder width of college students is estimated as the average of ordinary women, with shoulder width of $38 \mathrm{~cm}$ and chest thickness of $25.7 \mathrm{~cm}$, height $165 \mathrm{~cm}$.

(4)Set personnel speed

According to the investigation and analysis of the evacuation speed of the on-site personnel [27],set the evacuation speed of people at different working surfaces, and the value of young women is $1.5 \mathrm{~m} / \mathrm{s}$ on the horizontal plane.Considering that the evacuation simulation is dense and crowded near the stairs, the value of $0.98 \mathrm{~m} / \mathrm{s}$ in the stair surface is taken into account.

(5) Behavioral pattern settings

The behavioral modes of Pathfinder software are the SFPE mode and steering mode. In the case of an emergency, site construction personnel exhibit three behavioral modes: the shortest distance behavioral mode, the consistent in -and -out behavioral mode, and the complete conformity mode[28]. According to the data analysis, approximately $20 \%$ of people will wait in line at the same place, while approximately $50 \%$ of people will choose another evacuation route. The steering mode can control the evacuation of personnel by combining path planning, the guidance mechanism, and collision processing. Therefore, this study selected the steering mode of emergency evacuation. 


\subsection{Analysis of evacuation simulation results}

(1) Results of evacuation simulation

The results of the evacuation simulation are shown in Figs. 15 and 16. A total of 960 people were evacuated, which took 328.3 seconds.Fig. 17 shows the density of people at the time of $28.5 \mathrm{~S}$ evacuation. It can be seen from the figure that the evacuation corridors and stair openings are the areas with the highest density of people, and traffic jams are likely to occur in the evacuation corridors and evacuation stairs.

(2)Safety determination

When fire breaks out in the college student apartment, the safe evacuation of people in the apartment mainly depends on the time required for safe evacuation $\left(T_{R}\right)$ and the available time for safe evacuation $\left(T_{A}\right)[29]$. The people in the apartment can be safely evacuated only when the following formula is satisfied, otherwise the scheme should be adjusted.

Required time for safe evacuation $\left(T_{R}\right) \leqq$ Available time for safe evacuation $\left(T_{A}\right)(2)$

Here, $\left(T_{R}\right)$ refers to the time needed for all people in the apartment to be evacuated to safety from the moment when the emergency is discovered; $\left(T_{A}\right)$ refers to the time limit after which the people in the apartment are exposed to the risk of external accidents after the occurrence of a fire.

Required time for safe evacuation $\left(T_{R}\right)=$ Alarm time $\left(T_{a}\right)+$ Response time $\left(T_{p}\right)+$ Evacuation time $\left(T_{m}\right)(3)$

In Eq. (3), $T_{m}$ refers to the time required to evacuate all the people in the apartment, and is jointly determined by human attributes, psychological factors, environmental characteristics, and other factors. Therefore, $T_{m}$ is highly uncertain. Hence, the evacuation time in domestic and overseas fire control design must be multiplied by a coefficient of 1.5-2. Additionally, $T_{a}$ refers to the time when some people in the apartment discover the accident and notify all other personnel. This study chooses the case to be equipped with a video surveillance system. It is assumed that the on-site personnel can quickly discover the abnormal situation when a fire occurs. Therefore, $T_{a}$ was set to $30 \mathrm{~s}$. Finally, $T_{p}$ refers to the response time of the people in the apartment after receiving instructions pertaining to the danger. Because a safety risk warning system and monitoring system were installed at the simulation project, the response time was considered to be relatively short, and was set to $30 \mathrm{~s}$.

Safety decision: $T_{R}=T_{R}=T_{a}+T_{p}+1.5 \times T_{m}=30+30+1.5 \times 328.3=552.45$ s. According to the above formula, the available time for safe evacuation is $400 \mathrm{~s}$. Moreover, the average shock time of buildings domestically and abroad is 5-7 minutes [31]; the shock time $\left(T_{A}\right)$ was set to $6 \mathrm{~min}$ in this study. The required time for safe evacuation $\left(T_{R}\right)>$ Available safe evacuation time $\left(T_{A}\right)$. Therefore, the safety assessment failed, and all personnel could not be evacuated to safety. 
(3)Optimize the layout of the staircase and the number of personnel in the apartment

Analyze the results of the first emergency evacuation:First of all, the number of people evacuated in the central staircase caused a large number of people to be crowded, and the number of people evacuated at the north entrance and exit of the first floor was too small, which affected the overall evacuation time. Therefore, a staircase is added on the north side of the apartment building to increase the evacuation capacity of the people on the north side, and at the same time, it can increase the utilization rate of the external entrances and exits on the north side.Secondly, the excessive number of people in college apartments affects the overall evacuation speed. Therefore, the number of people carrying in the apartments is reduced, and all 6-person dormitories are converted into 4-person dormitories. The number of people simulated for the second emergency evacuation was reduced to 616 , and the optimized layout and personnel settings of the stairwell are shown in Fig. 18. The emergency evacuation simulation was restarted.

As shown in Fig. 19, the total time used in this simulation was169.5s. The time required for safe evacuation is $T_{R}=T_{a}+T_{p}+1.5 \times T_{m}=30+30+1.5 \times 169.5=314.25 s, T_{R}=314.2 S \square T_{A}=360.0 S$, which satisfies the code requirements for the design of building fire prevention measures. Fig. 20 shows the efficiency of each staircase and entrance.

\section{Conclusion}

The following conclusions were drawn from this study:

(1) When a fire occurs, the temperature variation at the fire source is the most obvious variation, and the temperature variation trend is approximately the same. The smoke rising through the stairwells and elevator shafts to the 13th floor is the main factor contributing to the filling of the middle area of the 6th floor with smoke.

(2) Through in-depth analysis, it can be seen that the efficiency of evacuation is related to the density of people, the relative position of people, and the degree of evacuation congestion. Severe detention and congestion in the stairwell position is the main reason that affects the efficiency of personnel escape, and it should be regarded as the primary safety hazard for fire emergency avoidance in reality.

(3) The visibility change characteristics have a guiding effect on the evacuation and rescue of personnel. In this numerical simulation, the optimal emergency rescue exit is the central escape exit.

(4) The total time of the first emergency evacuation was $552.45 \mathrm{~s}$. By analyzing the data collected by the temperature sensor, $\mathrm{CO}$ concentration sensor, and visibility sensor in the scene, it was found that the visibility and shock time are the key factors that negatively affect the evacuation efficiency. At $400 \mathrm{~s}$, the visibility of the exit of the college student apartment was less than $5 \mathrm{~m}$. The building crash time was $360 \mathrm{~s}$, which reaches the danger point for casualties. When the time required for safe evacuation $\left(T_{R}\right)>$ 
available time for safe evacuation $\left(T_{A}\right)$, the safety assessment fails, and the personnel cannot be completely evacuated to safety.

(5) By increasing the evacuation stairs on the north side, reducing the number of people in the construction plane, ensuring that the evacuation stairs are unobstructed, and actively providing evacuation guidance can effectively shorten the evacuation time. The second simulation shows that the safe evacuation time $\left(T_{R}\right)$ is $314.25 \mathrm{~s}$, and the required safe evacuation time $\left(T_{R}\right)<$ the available safe evacuation time $\left(T_{A}\right)$, which meets the requirements of the building fire protection design code.

(6) This study uses Pyrosim software and Pathfinder software to conduct fire numerical simulation research and numerical simulation of safety emergency evacuation for college student apartments, and guides personnel to evacuate and escape. The research was based on the fixed fire point, fire spread and evacuation of people. On the foundation of previous research, the further research which focuses on the planned number of stairwells and the load distribution of personnel on each floor will achieve more significant results.

\section{Declarations}

Author Contributions

\# J.W.contributed equally to this work.

\section{Notes}

The authors declare no competing financial interest.

\section{Acknowledgments}

This work was financially supported by the Youth Project of Liao ning Provincial Education Department (No. LJ2019QL019)】the National Key R\&D Program of China (No. 2018YFC0807900) and Liaoning Revitalization Talents Program $₫$ No. XLYC2008021区. These supports are gratefully acknowledged. The authors are grateful to the reviewers for discerning comments on this paper.

\section{Data Availability}

The data that support the findings of this study are available from the corresponding author upon reasonable request.

\section{References}

1. CCTV Network. On average, more than half of the fires in student dormitories are caused by electrical wiring failures every day(EB/OL).(2019-11-

07).http:||news.cctv.com/2019/11/07/ARTlyaTS4aXw6aNRbMjEHFy1191107.shtml. 
2. Helbing D,Farkas I J,Molnar P,et al. Simulation of pedestrian crowds in normal and evacuation situations[J].Pedestrian and evacuation dynamics.2002,21:21-58.

3. Hadjisophocleou G. Using a CFD simulation in designing a smoke management System in a building[J]. Proceedings of the 2006 Simulation Conference. 2006(7):2071-2076.

4. Manh Hung Nguyen, Tuong Vinh Ho, Thi Ngoc Anh Nguyen, Zucker, J. D. Which Behavior Is Best in a Fire Evacuation: Simulation with the Metro Supermarket of Hanoi[P]. Computing and Communication Technologies, Research, Innovation, and Vision for the Future (RIVF), 2012 IEEE RIVF International Conference on,2012.

5. Kirchner A, Schadschneider A. Simulation of evacuation processes using a bionics inspired cellular automaton model for pedestrian dynamics[J]. Physica A Statistical Mechanics \& Its Applications, 2002, 312(1):260-276.

6. J.M.WU,Y.H.LI,H.B.DU. Research on the Mental State and Behavior Characteristics of People in Fire[J]. China Work Safety Science and Technology,2007(03):35-38.

7. Y.Q.XU, Z.D.WANG. Research on evacuation of people under fire based on Pathfinder and FDS[J]. China Work Safety Science and Technology,2012,8(02):50-54.

8. W.D.YAN.Research on the behavior of people and evacuation time during building fire[D]. Northeastern University, 2006.

9. J.QIN.Research on human psychology and behavior in building fire[J]. Journal of Guangxi University for Nationalities (Natural Science Edition),2016,22(S1):120-123.

10. B.L.LI, Y.Y.GUAN.Psychological and behavioral characteristics of people in high-rise building fires[J]. City and Disaster Reduction,2004(03):8-10.

11. X.LIU, L.WANG.Psychological analysis of human behavior during fire in high-rise residential buildings[J]. Low Temperature Building Technology,2013,35(11):34-35.

12. W.G.SONG,Y.F.YU,T.CHEN.The impact of export conditions on evacuation and its analysis [J]. Fire Science, 2003(02):100-104+121.

13. P.H.ZHANG,B.Z.CHEN.The law of evacuation behavior during fire[J].Journal of Northeastern University, 2001(01):54-56.

14. E.Y.DU,X.R.CHEN,X.L.HAN,T.SONG.Research on the emergency evacuation of student groups in typical college buildings[J]. Journal of Huzhou Teachers College,2021,43(04),81-88.

15. S.J.LONG,B.ZHU,M.J.TANG,etc.Study on Fire Escape Simulation of College Student Dormitory Building[J]. Journal of Zunyi Normal University,2016,18(3):102-105.

16. Y.J.LI.Research on the emergency evacuation rules and fire protection countermeasures of college apartments: Taking a middle and low-rise dormitory in a college as an example [D].Beijing: China University of Mining and Technology,2019.

17. Y.J.HE,J.ZENG,Z.H.WANG,etc.Study on fire evacuation simulation and escape behavior of high-rise student dormitories[J]. Fire Science and Technology,2013,32(1):15-18. 
18. Mufeng Xiao,Xihua Zhou,Yanchun Han,Gang Bai,Jue Wang,Xianlin Li,and Shengnan Sunya.Simulation and optimization of fire safety emergency evacuation in university library[J].AIP Advances11,065323(2021).

19. S.C.TIAN,Y.CHEN,X.Q.SHEN, etc.Evacuation simulation and optimization of exit shape based on Pathfinder[J]. Fire Science and Technology,2018,37(12):1660-1662.

20. J.Y.YUAN,Y.P.CHENG,L.F.YE,etc.Study on the influence of staircase location on the evacuation safety of college dormitory buildings[J]. Fire Science and Technology,2018,37(9):1195-1198.

21. J.WANG,W.WANG,Q.C.KE,etc. Research on the evacuation simulation of a university library based on Pathfinder[J]. Security Technology,2011,(6):3-7.

22. M.G.YU,J.CHEN,G.F.SU.Numerical simulation study of fire smoke movement in cabin fire under different smoke prevention and exhaust methods[J].China Work Safety Science and Technology,2017,13(02):119-125.

23. S.Z.YANG,S.J.MO,Q.H.PAN.Numerical simulation study of fire smoke control in underground transportation hub station[J]. China Work Safety Science and Technology,2012,8(12):48-52.

24. Y.H.HE,J.GUO,H.B.WANG.Overview of the hazard characteristics of thermal disasters in civil aviation lithium battery transportation[J]. Journal of Civil Aviation,2019,3(03):88-90+52.

25. F.LIU,S.J.LIAO. Performance-based design of building fire protection [M]. Chongqing: Chongqing University Press,2006.

26. GB/T10000-1988, Chinese adult human body size[S]. Beijing: China Standard Press,1988.

27. J.M.WU.Research on the safe evacuation of laborers on the construction site based on BIM[D]. Xi'an: Xi'an University of Architecture and Technology,2015.

28. H.LIU. Research on the construction safety management of prefabricated concrete buildings based on BIM [D]. Xuzhou: China University of Mining and Technology,2019.

29. H.CAO. Study on Fire Safety Evacuation Design Strategy of Building Complex [D]. Shanghai: Tongji University,2006.

\section{Figures}



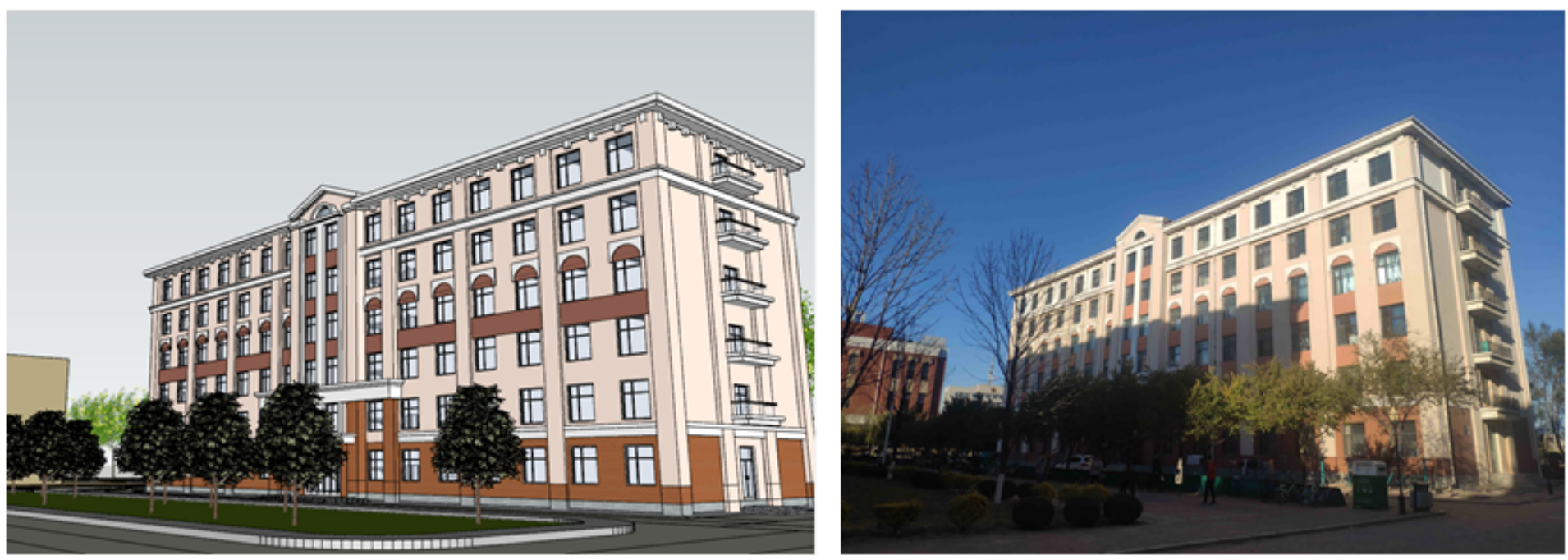

\section{Figure 1}

Comparison of BIM model and on-site photos of the student dormitory of Liaoning Technical University

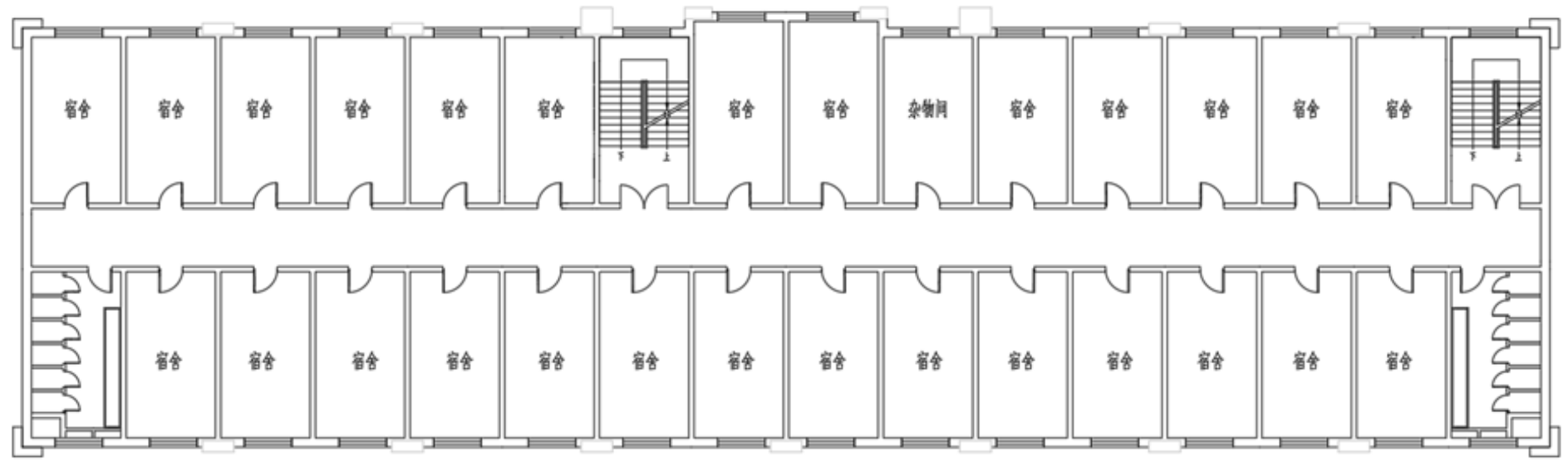

Figure 2

Layout of the standard floor of the student apartment of Liaoning Technical University 


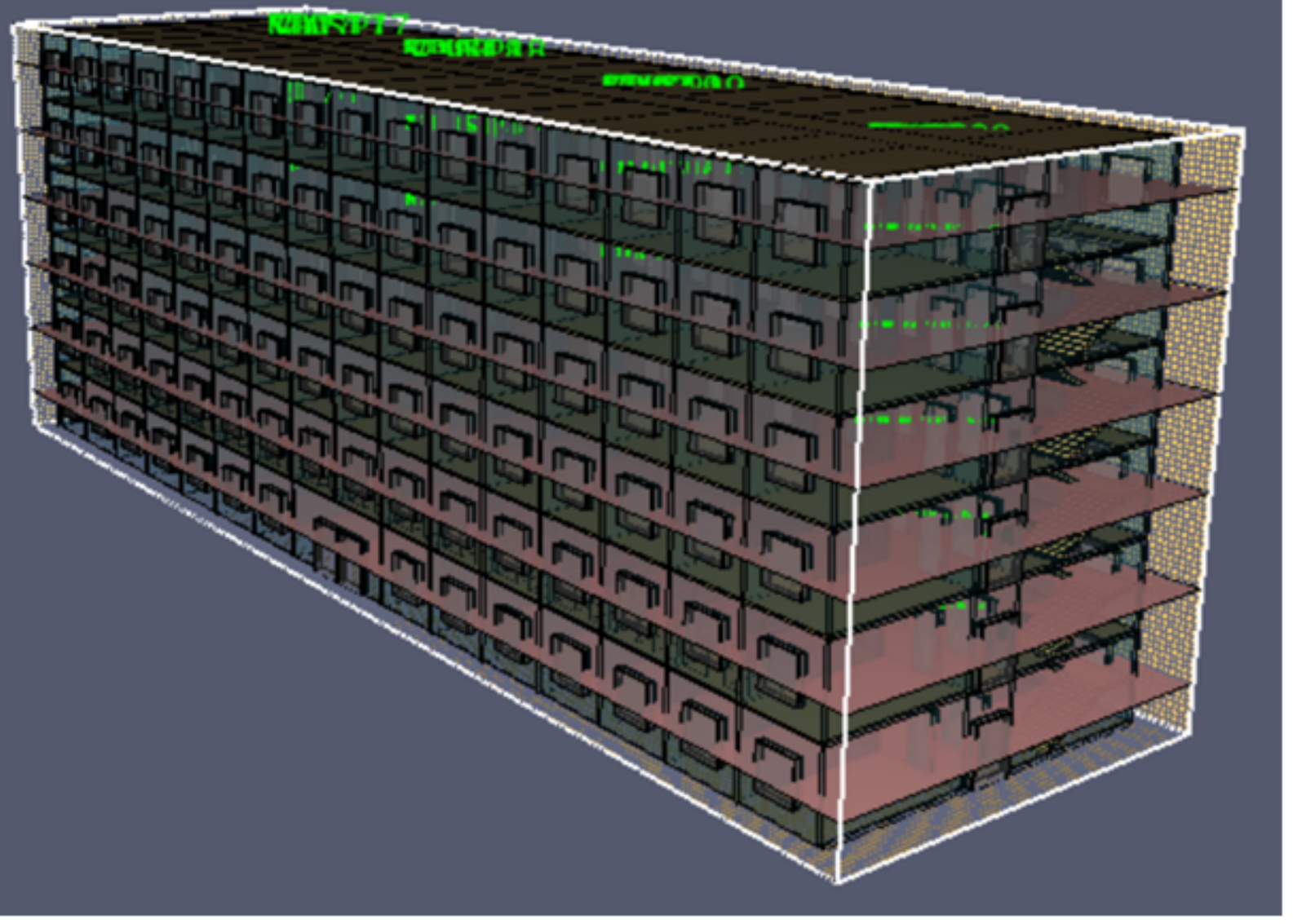

Figure 3

PyroSim model diagram.

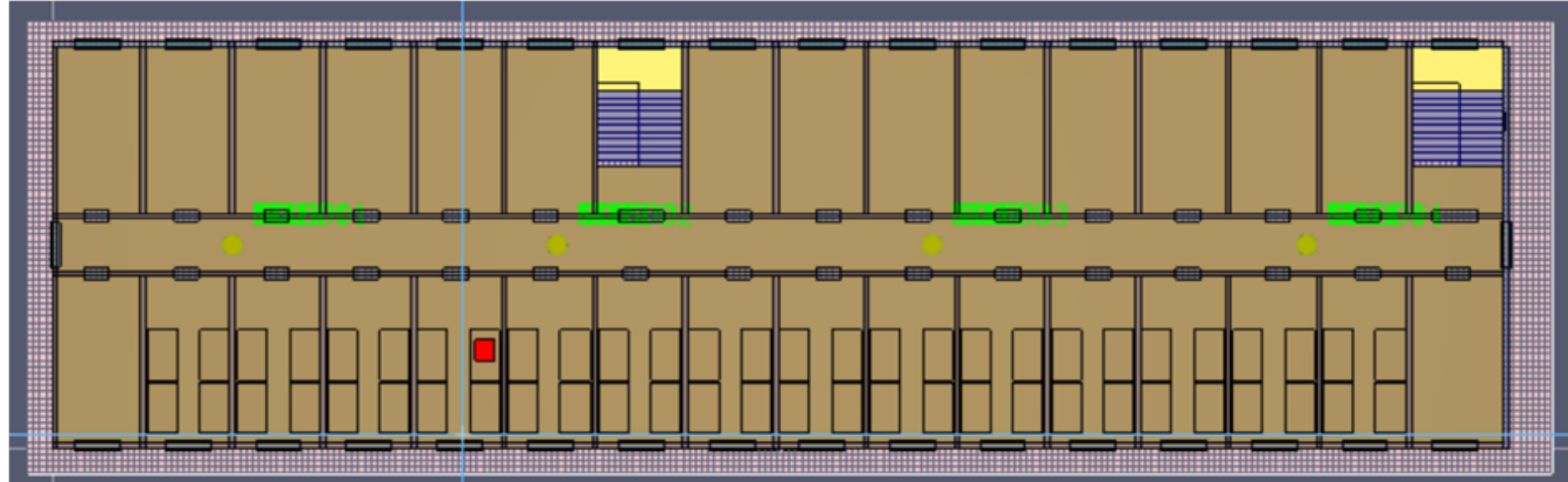

Figure 4

PyroSim Standard layer plan. 


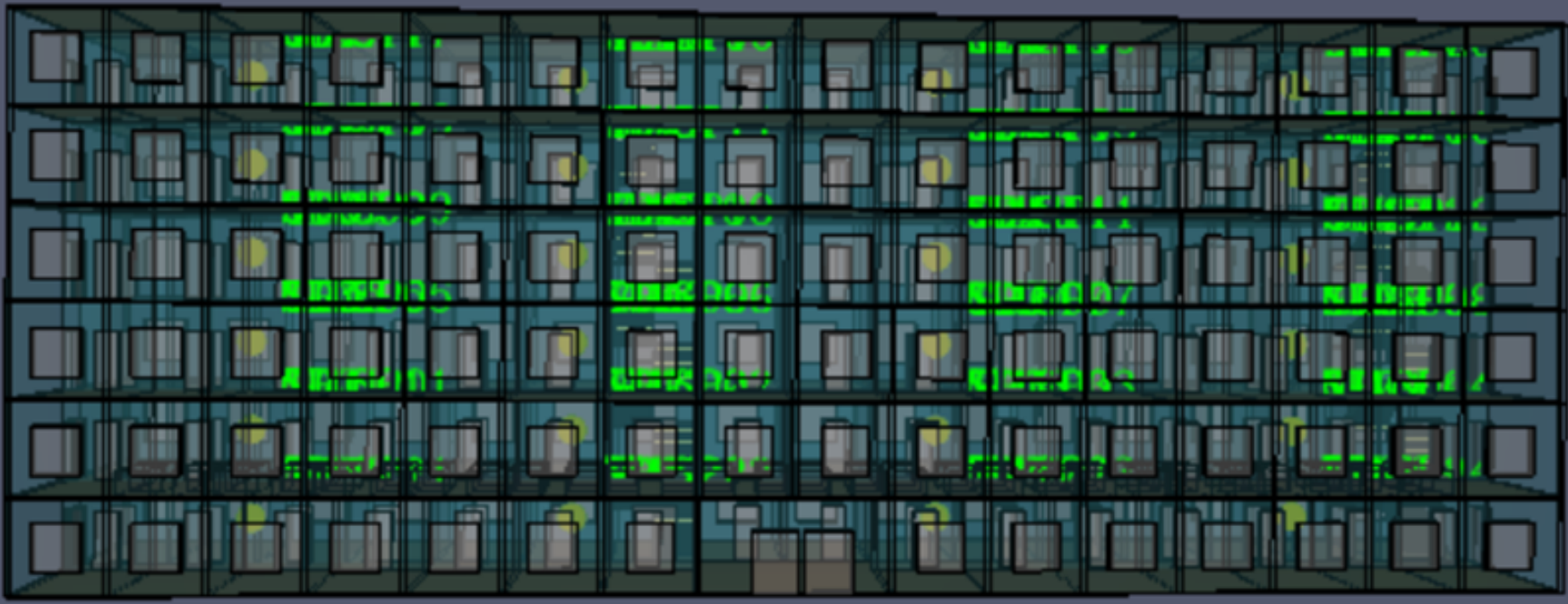

Figure 5

Sensor relative position diagram. 

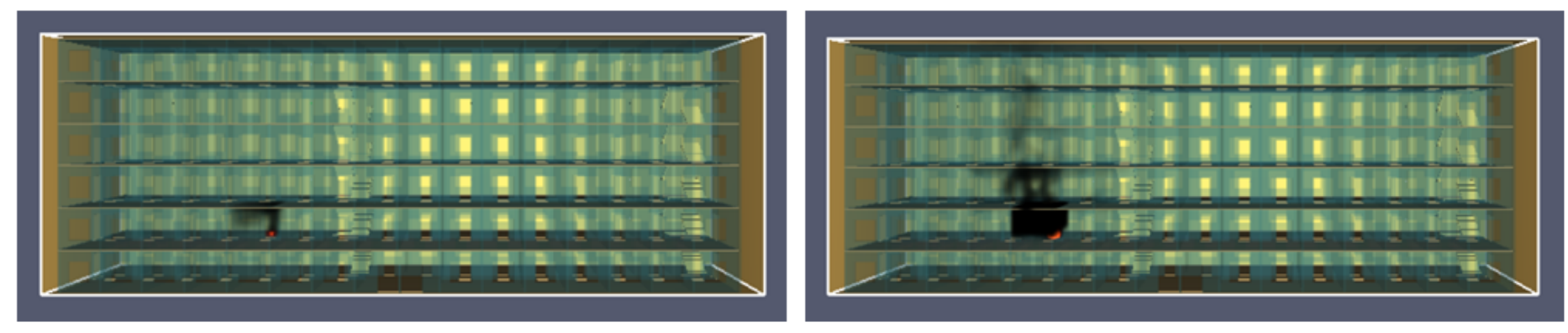

(a) $30 \mathrm{~S}$

(b) $90 \mathrm{~S}$
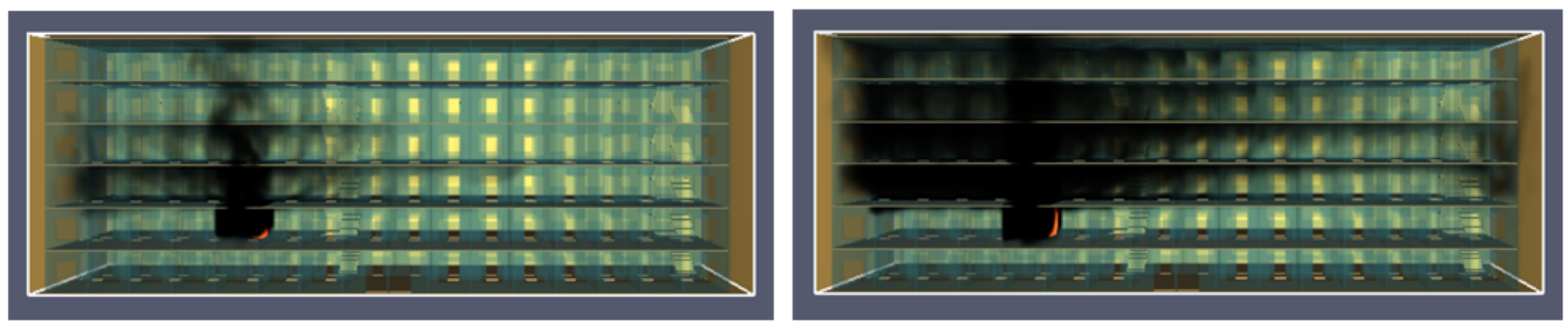

(c) $150 \mathrm{~S}$

(d) $270 \mathrm{~S}$
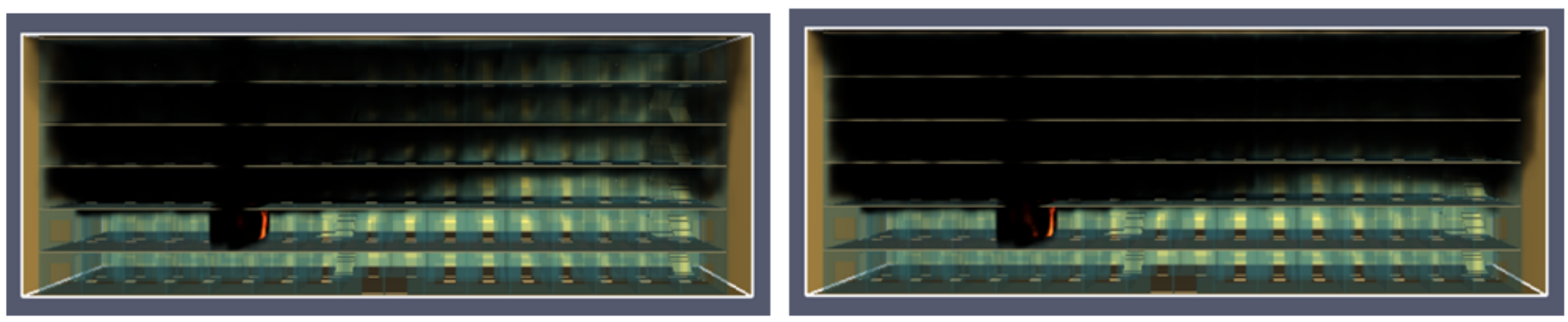

(e) $360 \mathrm{~S}$

(f) $480 \mathrm{~S}$

Figure 6

Chart of smoke spread. 


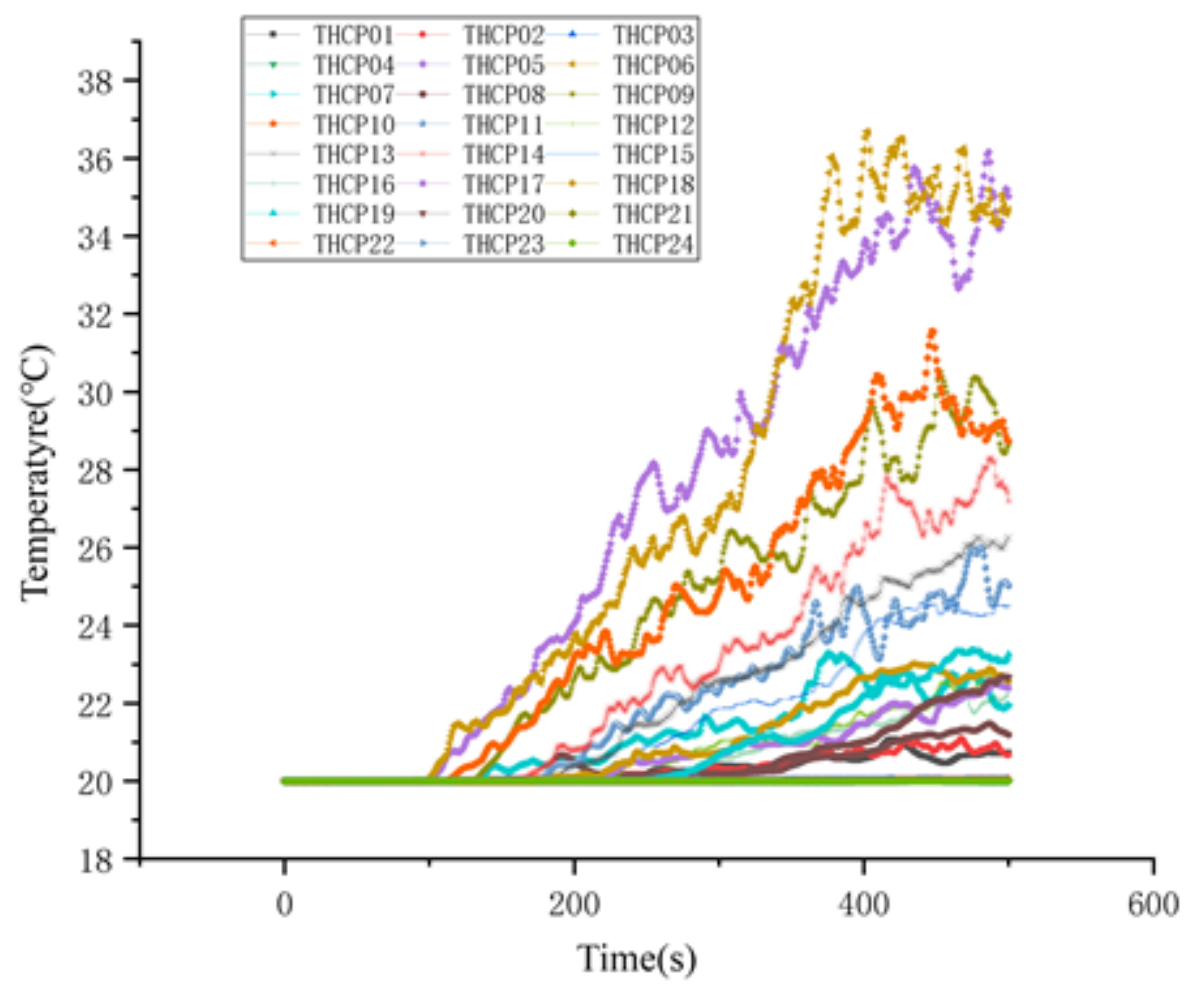

Figure 7

Temperature change graph.

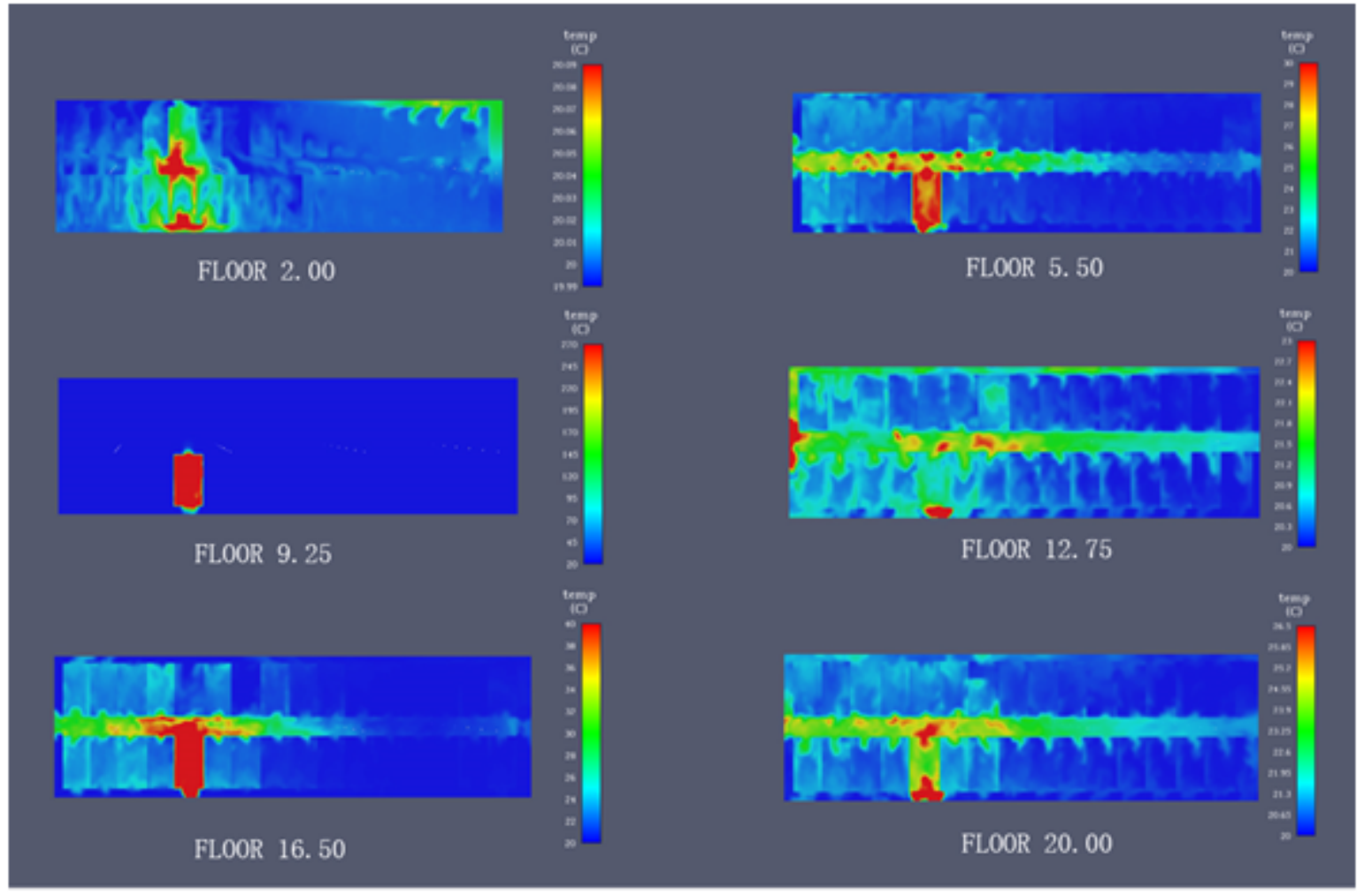

Figure 8 
Slice diagram of temperature change

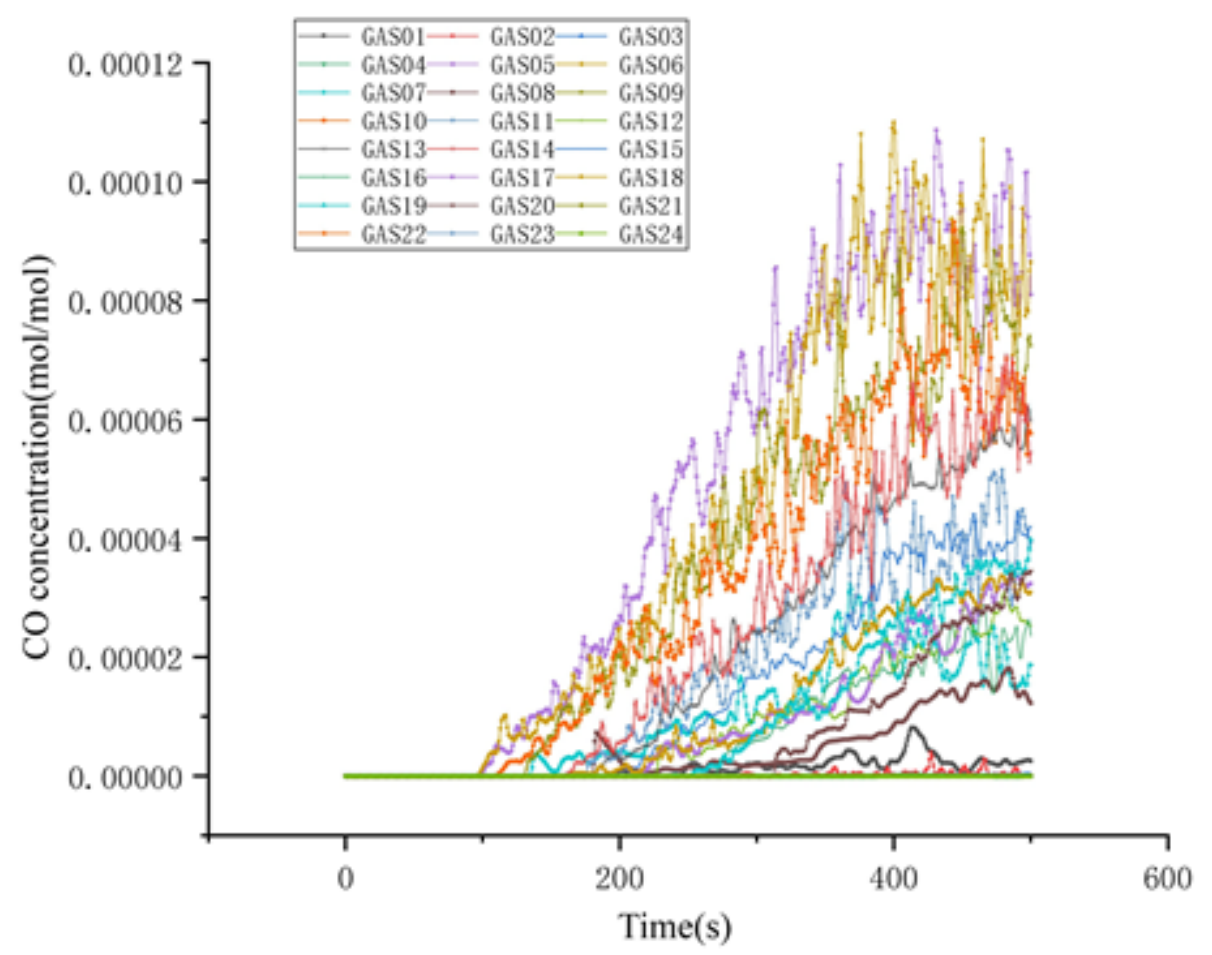

Figure 9

Curve of $\mathrm{CO}$ concentration change.

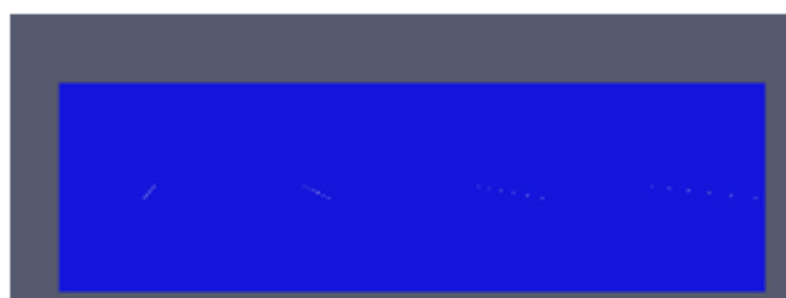

FLOOR 2.00

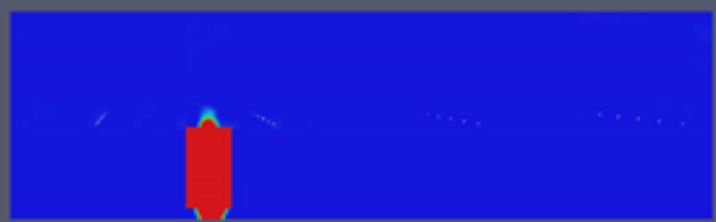

FLOOR 9. 20

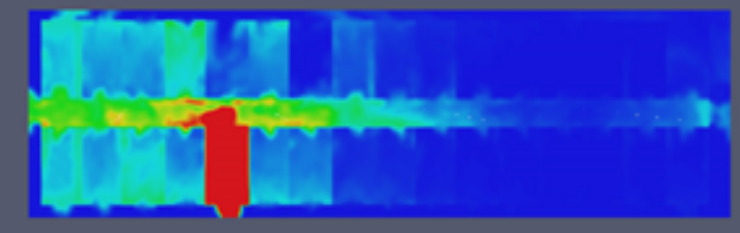

FLOOR 16. 40

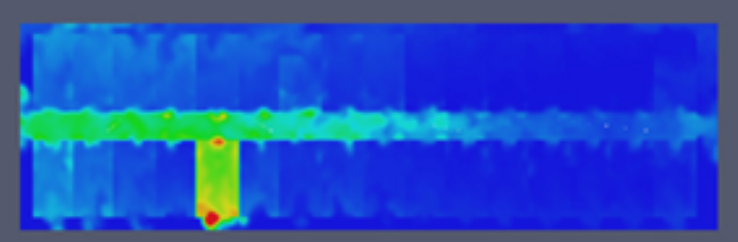

FLOOR 5. 60

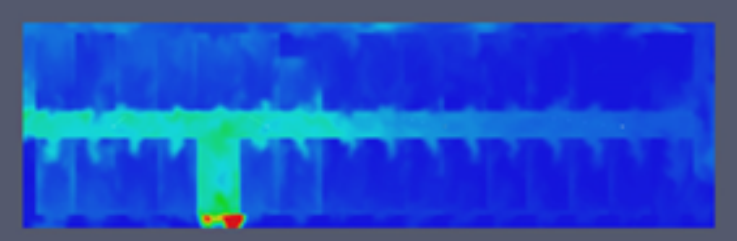

FLOOR 12.80

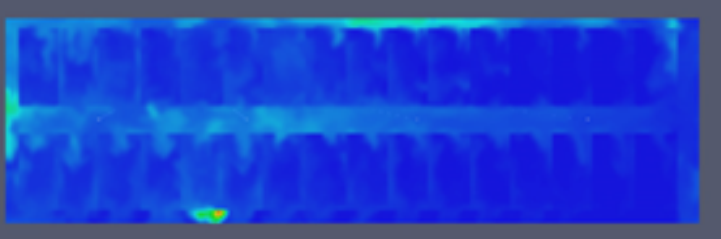

FLOOR 20.00 
Figure 10

Section diagram of $\mathrm{CO}$ concentration change.

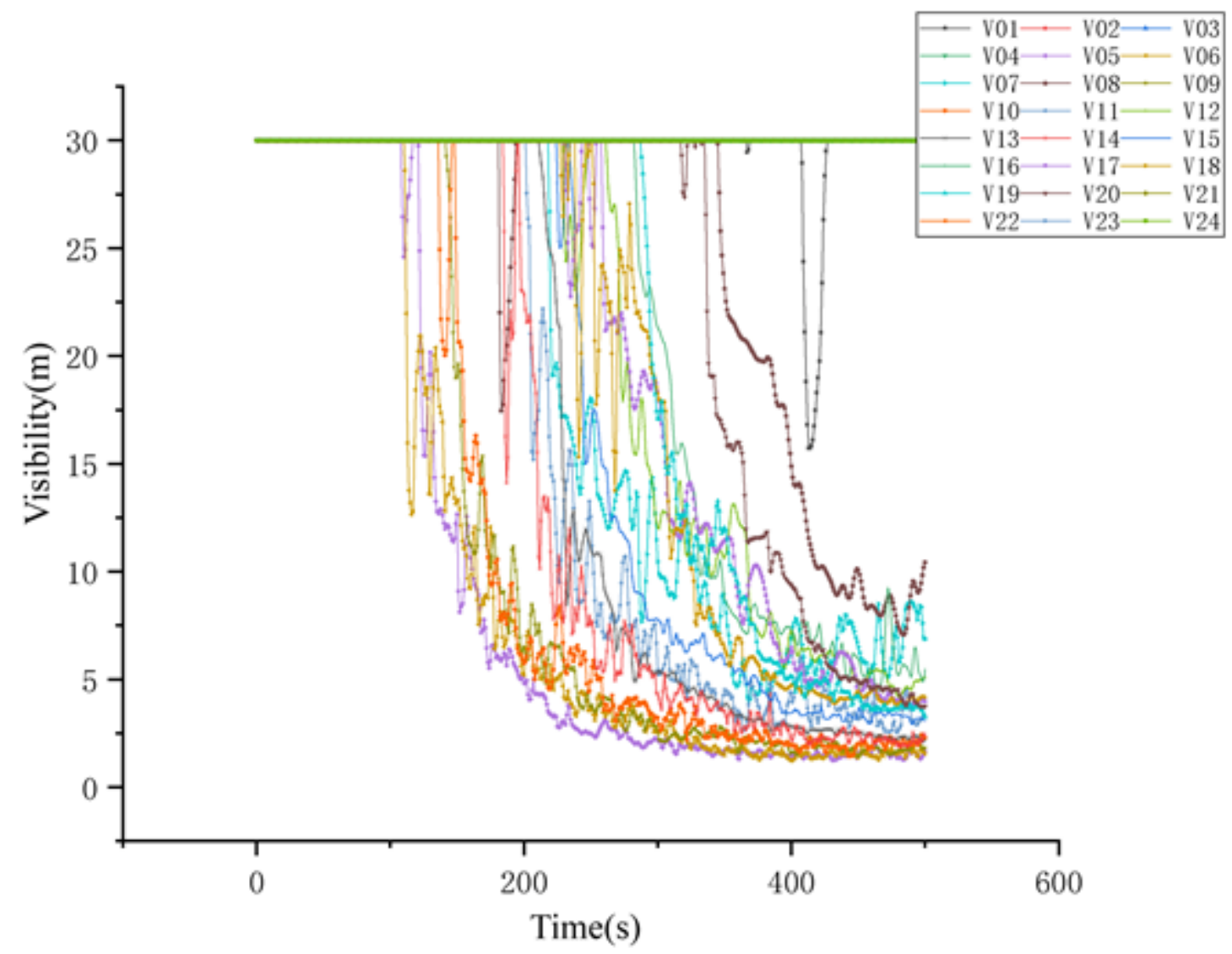

Figure 11

Visibility change chart. 
FLOOR 2. 00

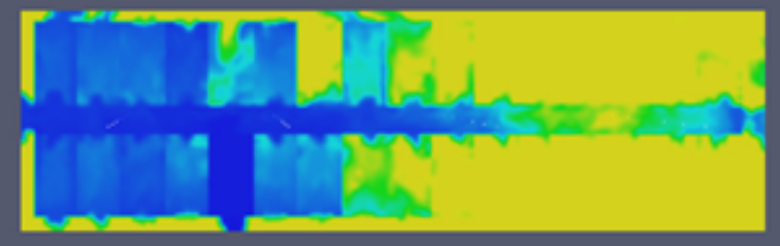

FLOOR 9. 20

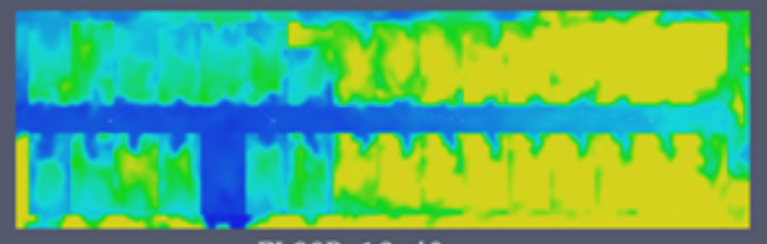

FLOOR 16.40

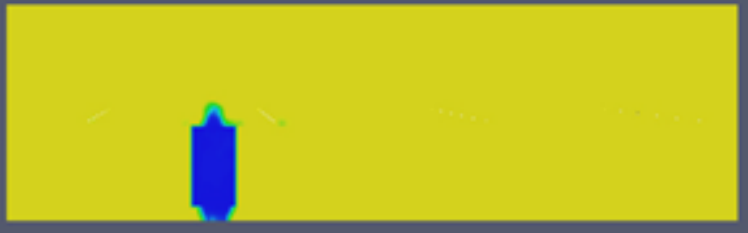

FLOOR 5. 60

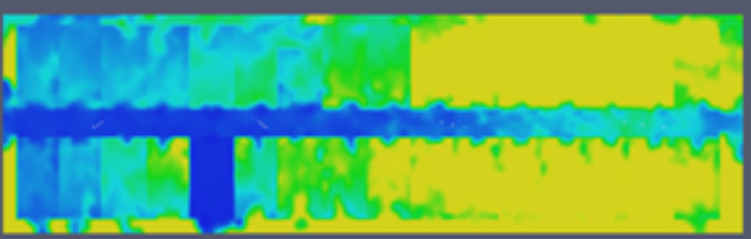

FLOOR 12.80

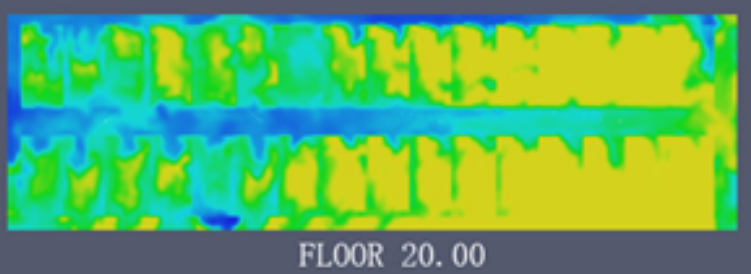

\section{Figure 12}

Slice diagram of visibility changes.

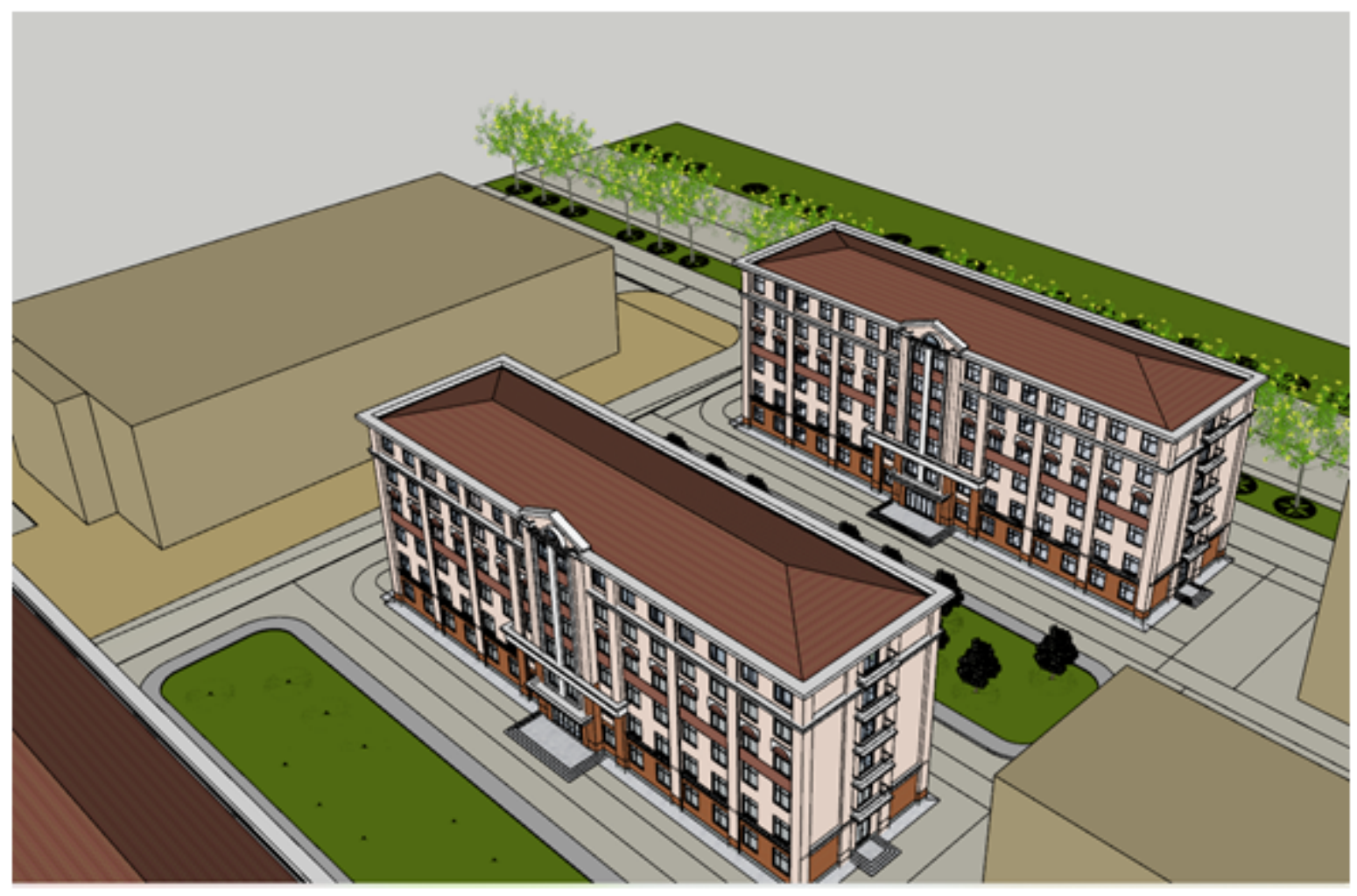


Figure 13

BIM security information model.

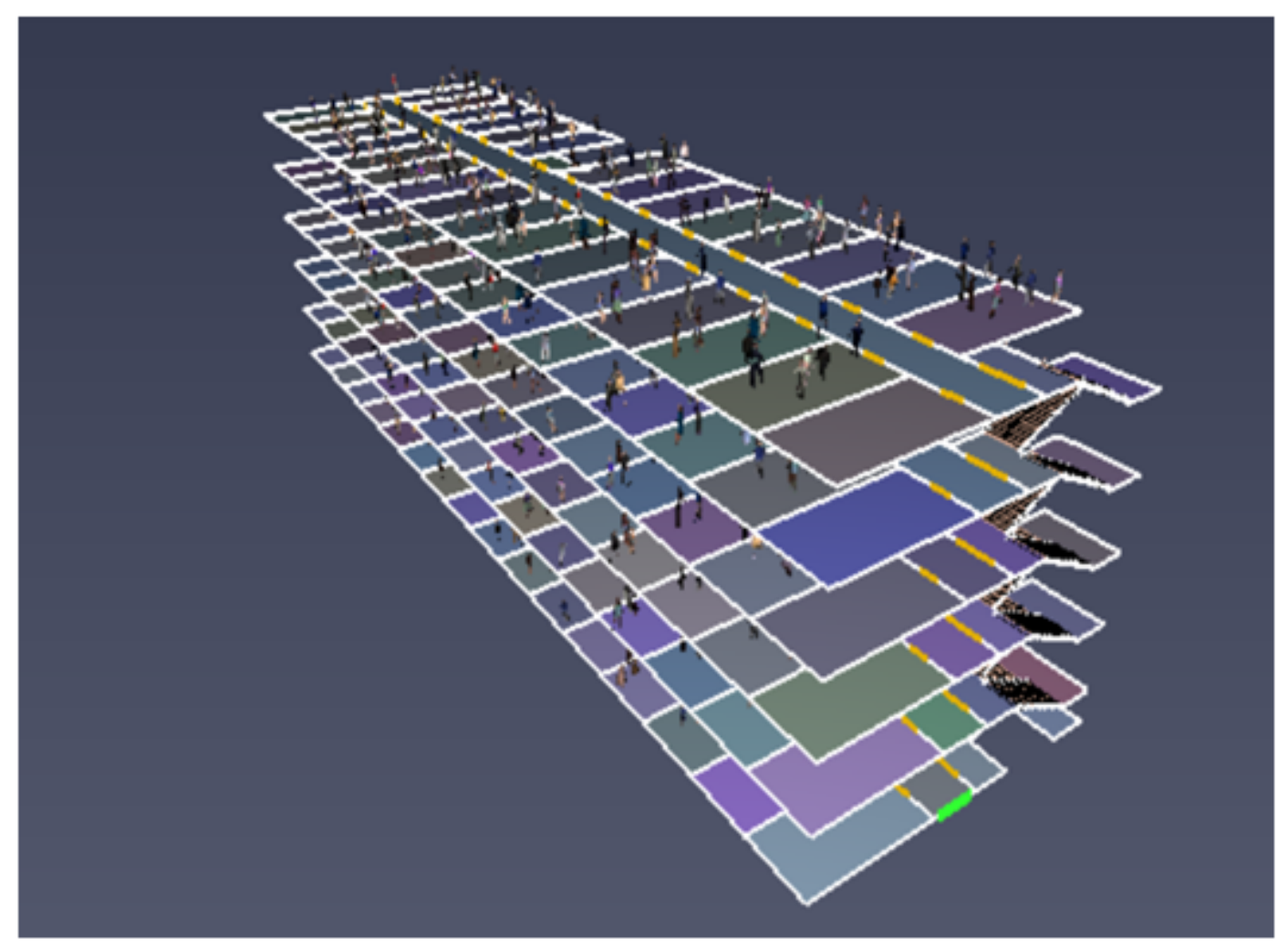

Figure 14

Pathfinder model of safe emergency evacuation. 


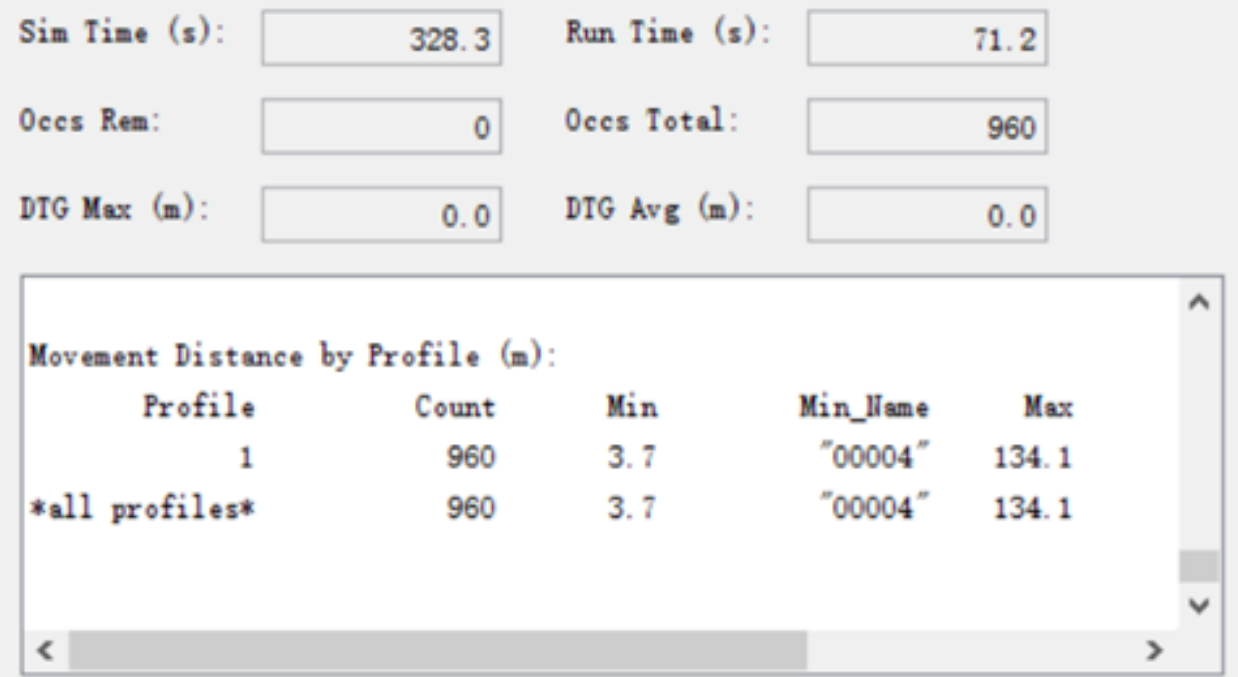

$\square$ Show results when finished

$\square$ Pause if occupants appear to be stuck

\begin{tabular}{|l|l|l|}
\hline Debug & Results & Pause \\
\hline
\end{tabular}

\section{Figure 15}

Total evacuation time. 


\section{Number of Occupants in Selected Rooms}

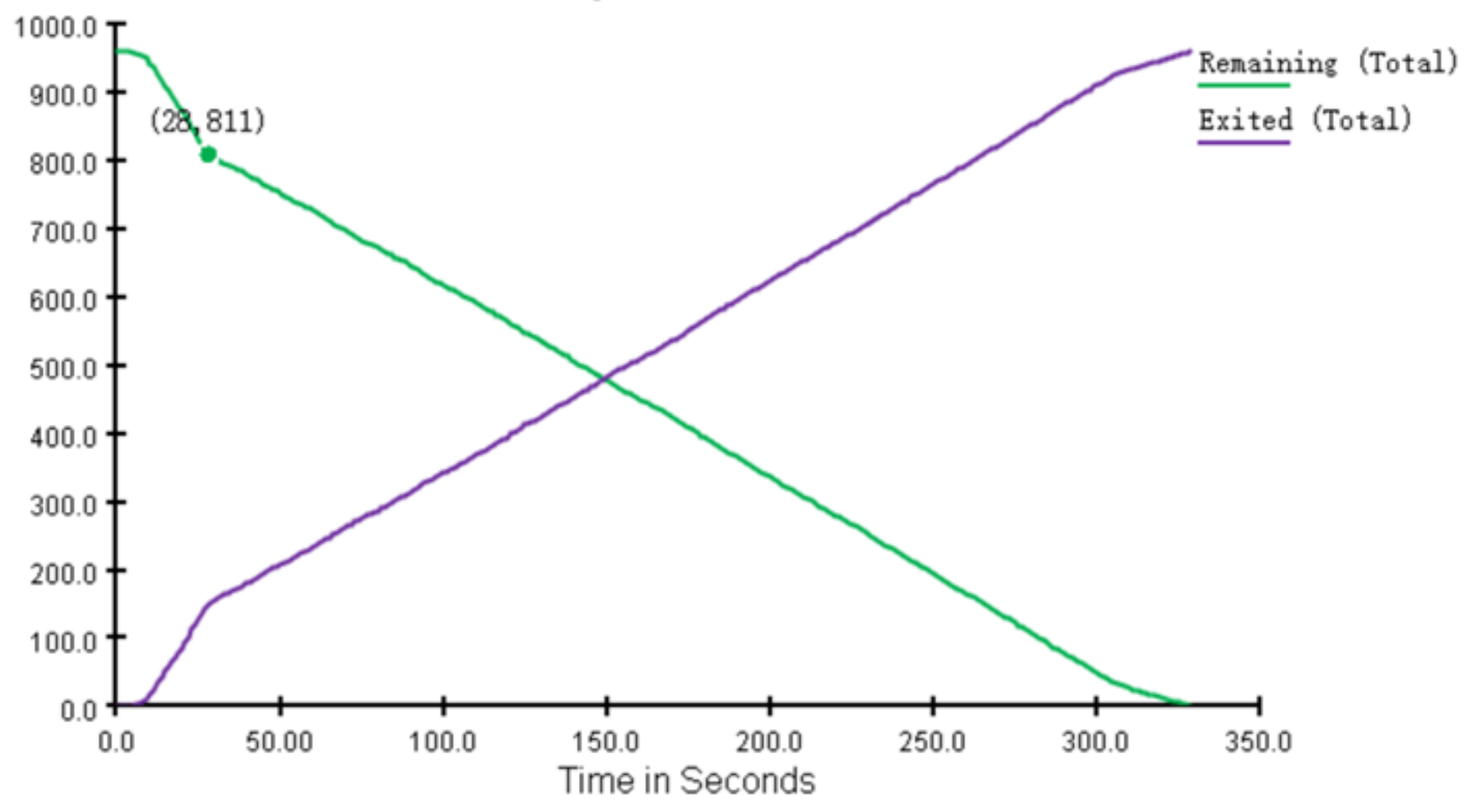

Figure 16

Evacuation time-number curve.
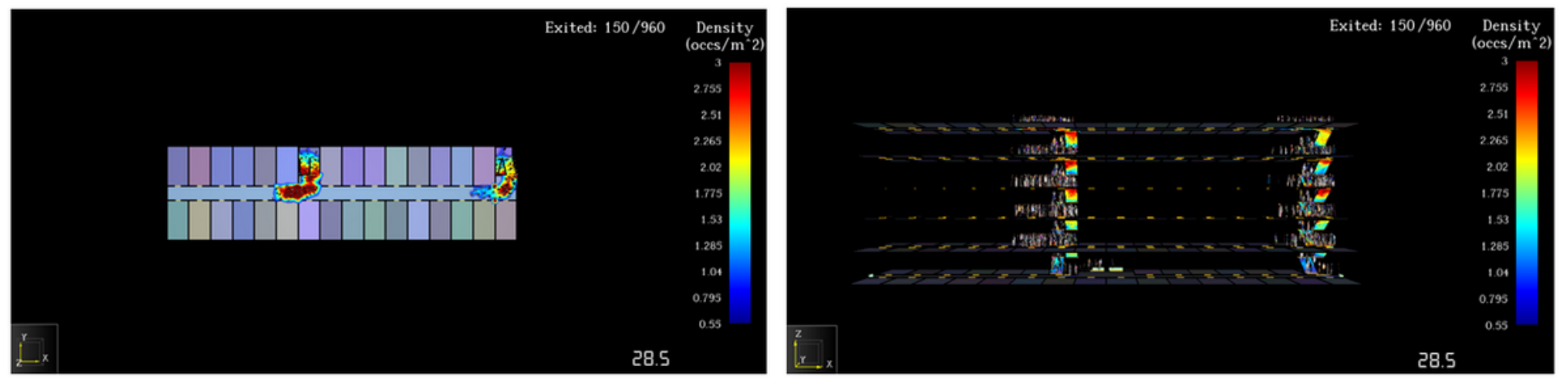

Figure 17

Personnel density map at evacuation time of $28.5 \mathrm{~s}$. 


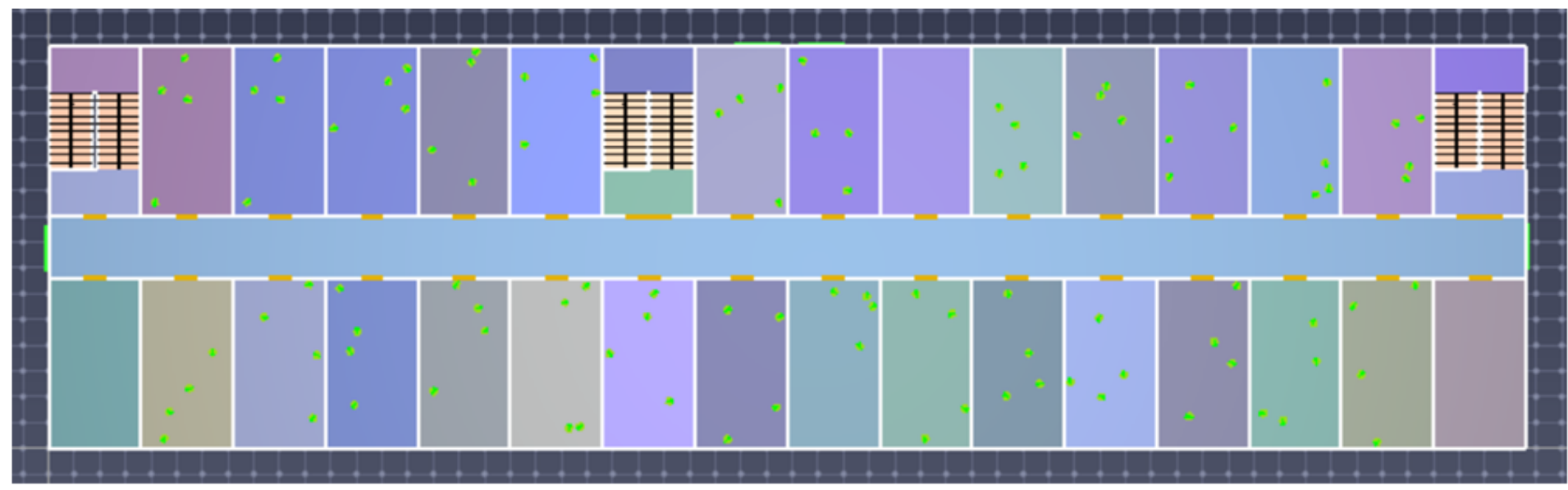

Figure 18

Optimized layout and personnel settings.

X Run Simulation - gongyu4 (2) pth

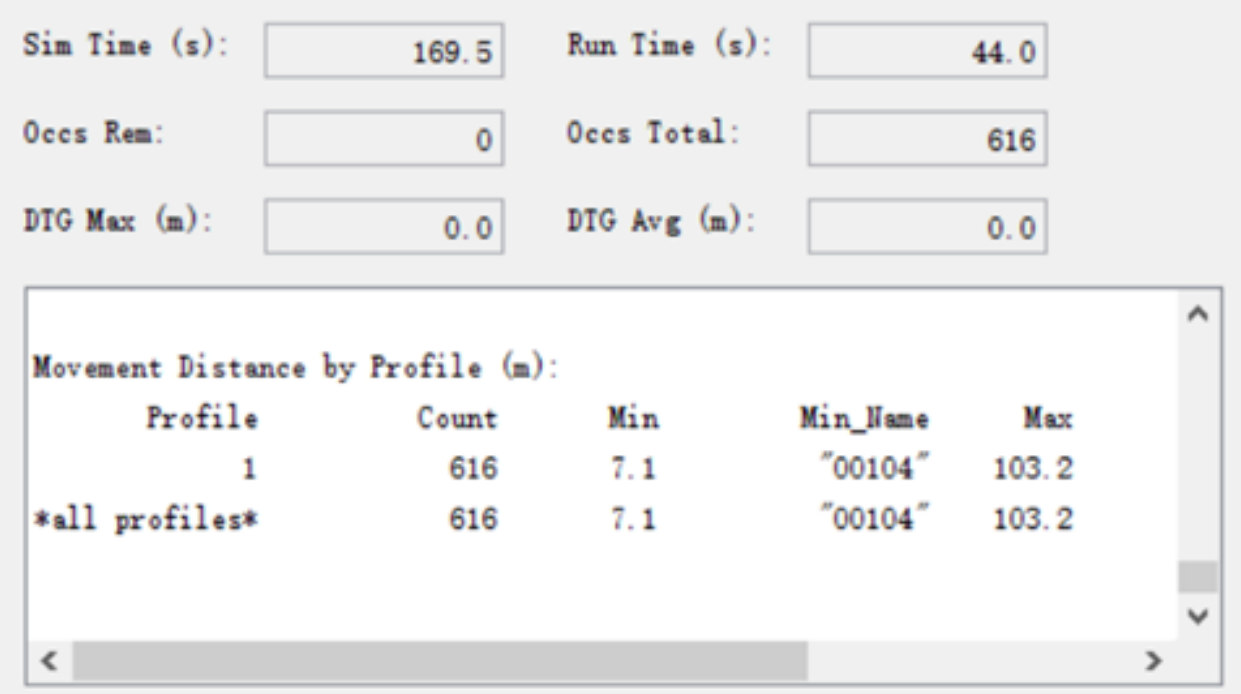

$\square$ Show results when finished

$\square$ Pause if occupants appear to be stuck

\begin{tabular}{|l|l|}
\hline Debug & Pesults \\
\hline
\end{tabular}

\section{Figure 19}

Total evacuation time (second simulation). 


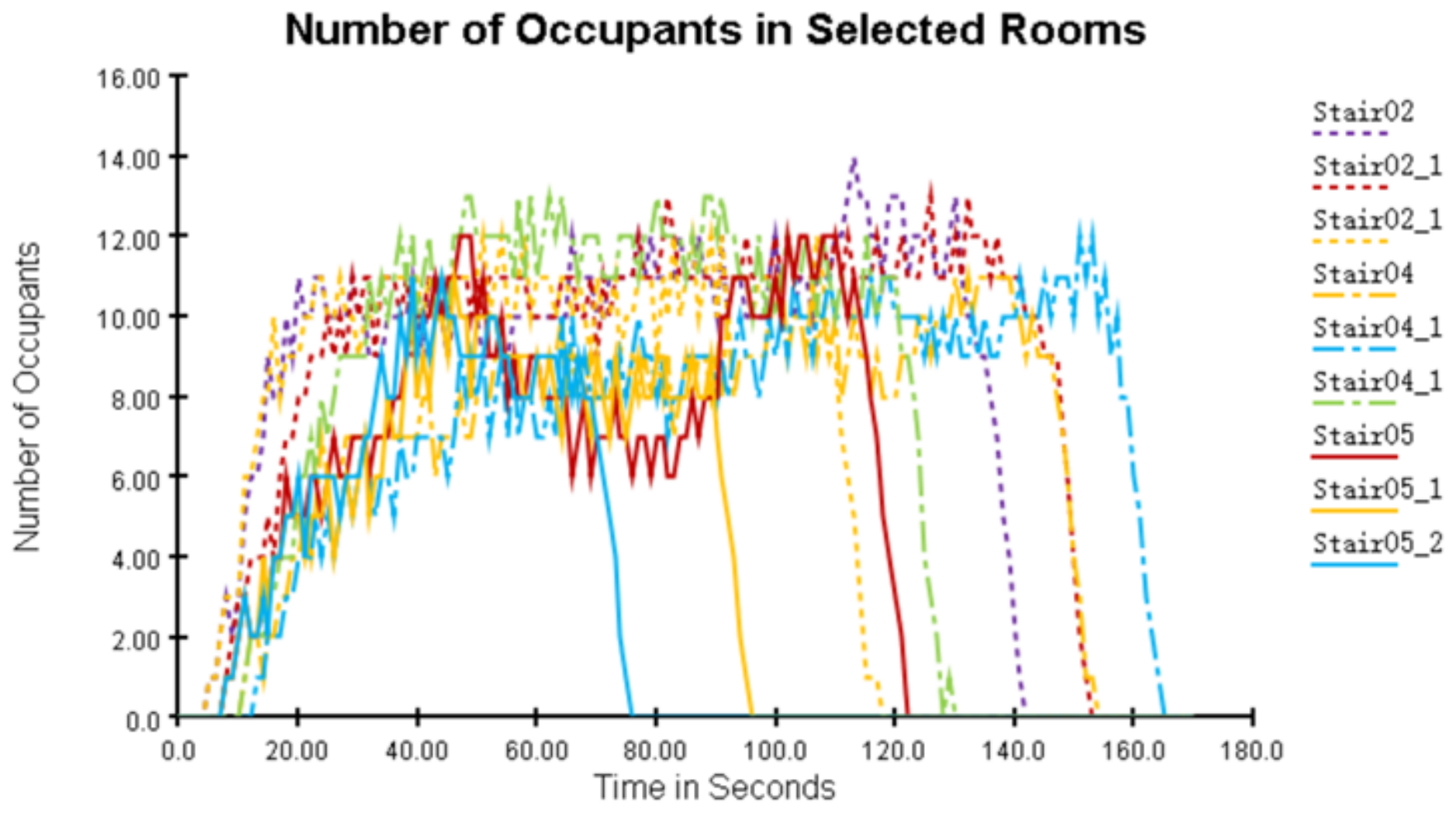

Figure 20

Changes in flow of people at each exit. 